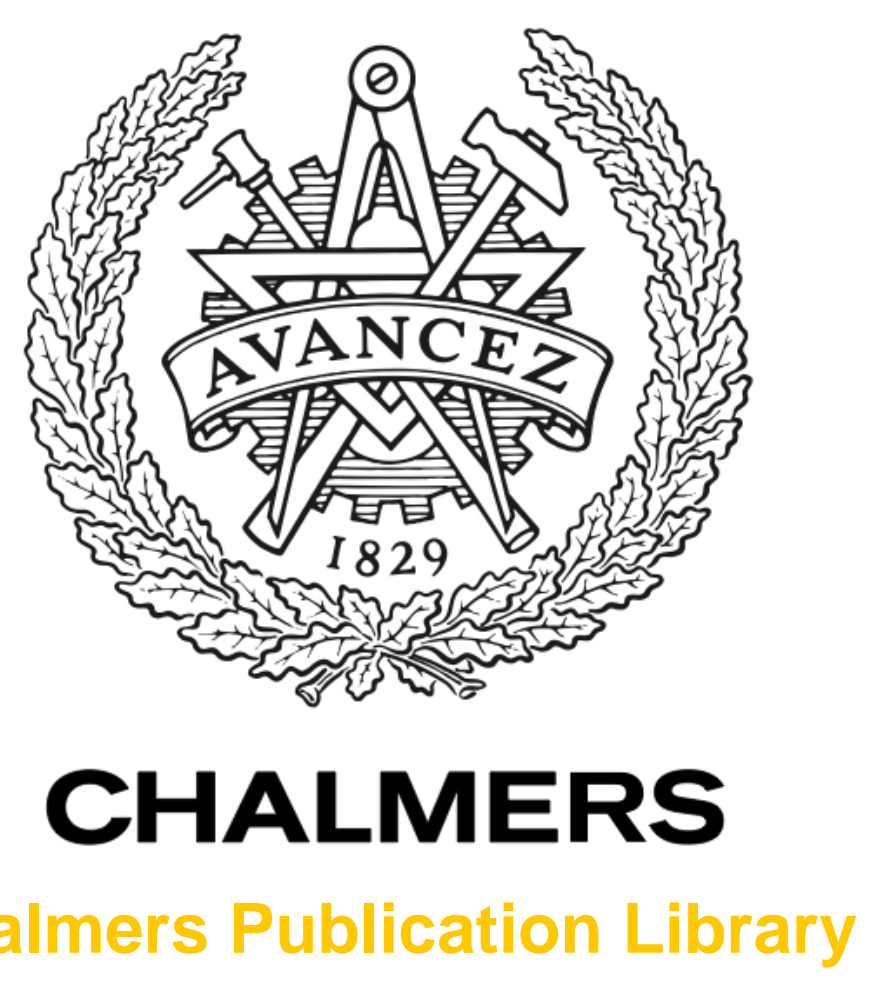

Chalmers Publication Library

\title{
Study On Wear Behaviors Of Ni3al/ Cr-Carbides Cladding Layer On High Strength Steel Substrate
}

This document has been downloaded from Chalmers Publication Library (CPL). It is the author's version of a work that was accepted for publication in:

Advanced Materials Research (2014)

Citation for the published paper:

Gong, K. (2014) "Study On Wear Behaviors Of Ni3al/ Cr-Carbides Cladding Layer On High Strength Steel Substrate". Advanced Materials Research (2014), vol. Vol. 936 pp. pp 12731282 .

Downloaded from: http://publications.lib.chalmers.se/publication/208664

Notice: Changes introduced as a result of publishing processes such as copy-editing and formatting may not be reflected in this document. For a definitive version of this work, please refer to the published source. Please note that access to the published version might require a subscription. 


\title{
Study On Wear Behaviors Of $\mathrm{Ni}_{3} \mathrm{al} / \mathrm{Cr}$-Carbides Cladding Layer On High Strength Steel Substrate
}

\author{
Karin Gong ${ }^{\mathrm{a} 1}$, An Tongbang ${ }^{\mathrm{b}}$, Zhifeng Zhou ${ }^{\mathrm{c}}$, Zhiling Tian ${ }^{\mathrm{b}}$, Changhai Li ${ }^{\mathrm{a}}$ \\ a Department of Materials and Manufacturing Technology, Chalmers University of Technology, SE- \\ 41296 Gothenburg, Sweden \\ ${ }^{\mathrm{b}}$ China Iron and Steel Research Institute Group (CISRI), Beijing 10081, P. R. China \\ ${ }^{c}$ Department of Manufacturing Engineering and Engineering Management (MEEM), \\ City University of Hong Kong, Kowloon, Hong Kong \\ akarin.gong@chalmers.se, b tianzhl@cisri.com.cn, c mezfzhou@cityu.edu.hk \\ ${ }^{1}$ Corresponding author: Tel.: +46 317721261 ; Fax: +46 7721313 \\ E-mail address: karin.gong@chalmers.se
}

Keywords: Friction coefficient; Specific wear rate; Intermetallics; Sliding wear; Cladding

\begin{abstract}
A cladding layer of $\mathrm{Ni}_{3} \mathrm{Al}$ matrix composite reinforced with 18 vol. \% Cr-carbides was applied by using tungsten inert gas (TIG) welding process on high strength steel substrate. The filler metal as welding wire prepared by horizontal continuous casting process with a composition of $\mathrm{Ni}$ 2.5C-30Cr-9Al-0.02B (in wt. \%) is used. A bulk material of NAC-alloy composite with 18 vol. \% $\mathrm{Cr}_{3} \mathrm{C}_{2}$-particles produced by Hot Isostatic Pressing (HIP) was also investigated as a reference material. The composition of NAC-alloy is Ni-9.87Al-11.63Fe-0.50Mn-0.50Ti-0.2B in weight percentage. The pin-on-disk (POD) tribometer tests were carried out at room temperature in dry sliding condition at a pressure of $2.83 \mathrm{MPa}(20 \mathrm{~N})$. The results revealed that $\mathrm{Ni}_{3} \mathrm{Al} / \mathrm{Cr}$-carbides cladded layer by TIG process improved wear properties significantly with very low values of the friction coefficient $(0.13 \pm 0.02)$ and the specific wear rate $\left(0.162 \times 10^{-5} \mathrm{~mm}^{3} / \mathrm{N} \cdot \mathrm{m}\right)$ as compared to the reference HIP processed composite with the friction coefficient $(0.68 \pm 0.02)$ and the specific wear rate $\left(0.908 \times 10^{-5} \mathrm{~mm}^{3} / \mathrm{N} \cdot \mathrm{m}\right)$ under the same testing conditions.
\end{abstract}

\section{Introduction}

High-temperature wear-resistant intermetallic materials have attracted recently material researchers' attention, especially the $\mathrm{Ni}_{3} \mathrm{Al}$-based materials. $\mathrm{Ni}_{3} \mathrm{Al}$-based alloys exhibit increased yield strength with increase of temperature to about $650-750{ }^{\circ} \mathrm{C}$, which made them an attractive engineering materials with good wear resistance. Due to these properties, $\mathrm{Ni} 3 \mathrm{Al}$-based alloys have significant potential in wear critical applications at temperature range between $400{ }^{\circ} \mathrm{C}$ and $650{ }^{\circ} \mathrm{C}^{[1-}$ ${ }^{6}$. Intermetallic matrix composites (IMC) with hard particles reinforcements are considered for wear applications in severe, i.e. chemically aggressive environments. For instance, chromium carbide reinforced $\mathrm{Ni}_{3} \mathrm{Al}$ matrix composite was developed as candidate wear resistant material under elevated temperatures ${ }^{[7]}$. Chromium carbides have very high hardness and good wetting ability with the $\mathrm{Ni}_{3} \mathrm{Al}$ matrix, and also excellent oxidation resistance ${ }^{[8]}$. Karin et al. ${ }^{[9]}$ illustrated that the addition of 6 vol. $\% \mathrm{Cr}_{3} \mathrm{C}_{2}$ particles reduced wear rates of the pin and the disk up to $50 \%$. Clearly, the characteristics of worn surfaces were recognized that the hard $\mathrm{Cr}_{3} \mathrm{C}_{2}$-asperities supported a couple of sliding surfaces apart during the sliding wear process, then reduced the specific wear rates of the pin and the disk. A surface modification by forming wear resistant layer on steel substrate is a useful technical method to produce components to resist against wear damages under severe wear condition. Therefore, chromium carbides reinforced $\mathrm{Ni}_{3} \mathrm{Al}$ composite cladded layer produced by tungsten inert gas (TIG) welding process was investigated in this study. A HIP processed bulk material of NAC-alloy composite with 18 vol. $\% \mathrm{Cr}_{3} \mathrm{C}_{2}$-particles was also investigated as a reference material. 


\section{Experimental Methods and Results}

\section{Testing Materials and Preparation}

The chemical composition of the steel substrate is Fe-0.35C-24Cr-8.5Ni-1.6Si-1.2Mn- $0.24 \mathrm{~N}-$ $0.25 \mathrm{Re}$ in weight percentage. The welding wire with composition of $\mathrm{Ni}-2.5 \mathrm{C}-30 \mathrm{Cr}-9 \mathrm{Al}-0.02 \mathrm{~B}$ in weight percentage was used for TIG welding process, which was prepared by means of horizontal continuous casting process. A vermicular graphite cast iron, a monolithic NAC-alloy and its composites prepared by HIP process were selected as reference materials. The vermicular graphite cast iron is usually used as piston ring material in engines. A grey cast iron was applied as counterpart disk material for tribo-test in this study. The designation of the tested samples is summarized in Table 1.

\section{TABLE 1 DESIGNATIONS OF THE TESTED SAMPLES}

\begin{tabular}{|llr|}
\hline Designation & \multicolumn{1}{c|}{ Composition (wt. \%) } & Process \\
\hline Pin 1 & \multicolumn{1}{c}{ Ni-2.5 C-30 Cr-9Al-0.02 B } & TIG \\
Pin 2 & Ni-9.87Al-11.63Fe-0.50Mn-0.50Ti-0.2B +18 vol.\% Cr3C2 & HIP \\
Pin 3 & Ni-9.87Al-11.63Fe-0.50Mn-0.50Ti-0.2B & HIP \\
Pin 4 & Fe-3.05C-1.20Si-0.85Mn-0.10 $\pm 0.05 P-0.05 S-0.65 \pm 0.05 \mathrm{Mo}-0.9 \pm 0.05 \mathrm{Cu}-0.02 \mathrm{~V}-0.03 \mathrm{Ti}$ & as-cast \\
Disk & Fe-3.20C-1.1Si-0.8Mn-0.2P-0.1S-0.02B-1.0Cu-0.22V & as-cast \\
\hline
\end{tabular}

During the TIG welding process, it was assumed that all of the C-content in the welding wire reacted with $\mathrm{Cr}$ and formed chromium carbides. Afterwards residual $\mathrm{Cr}$-content $\sim 11 \mathrm{wt}$. \% will be dissolved in the $\mathrm{Ni}_{3} \mathrm{Al}$ alloy matrix and formed $\mathrm{Cr}$-rich $\mathrm{Ni}_{3} \mathrm{Al}$ phase. By taking the densities of the $\mathrm{Ni}_{3} \mathrm{Al}$-matrix and chromium carbides as $7.25 \mathrm{~g} / \mathrm{cm}^{3}$ and $6.68 \mathrm{~g} / \mathrm{cm}^{3}$ from the previous study into consideration, the volume percentage of $\mathrm{Cr}$-carbides formed in the welding wire alloy was calculated $\sim 18$ vol. $\%$. Therefore, 18 vol. $\% \mathrm{Cr}_{3} \mathrm{C}_{2}$-particles were added to obtain HIP processed bulk $\mathrm{Ni}_{3} \mathrm{Al}$-matrix composite and selected as reference material for studying the influence of the microstructure on tribological behavior. Table 2 showed three different welding parameters were applied in TIG process.

TABLE 2 WELDING PARAMETERS IN TIG PROCESS

\begin{tabular}{|c|c|c|c|c|c|}
\hline & $\begin{array}{c}\text { Voltage } \\
{[\mathrm{V}]}\end{array}$ & $\begin{array}{c}\text { Current } \\
{[\mathrm{A}]}\end{array}$ & $\begin{array}{c}\text { Argon flow rates } \\
{[\mathrm{L} / \mathrm{min}]}\end{array}$ & $\begin{array}{c}\text { Welding speed } \\
{[\mathrm{mm} / \mathrm{s}]}\end{array}$ & Cooling \\
\hline $1^{\#}$ & $10 \sim 12$ & 50 & 8 & 0.4 & air \\
\hline $2^{\#}$ & $10 \sim 12$ & 70 & 10 & 0.8 & air \\
\hline $3^{\#}$ & $10 \sim 12$ & 90 & 10 & 0.8 & air \\
\hline
\end{tabular}
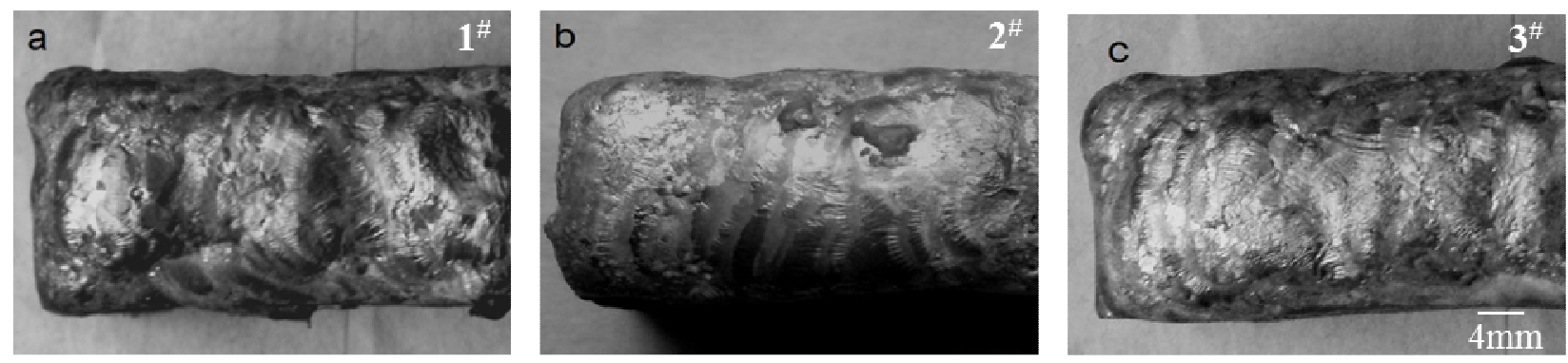

Fig. 1 Top Views of the Cladded Layer Prepared by Three Different TIG Process Parameters 

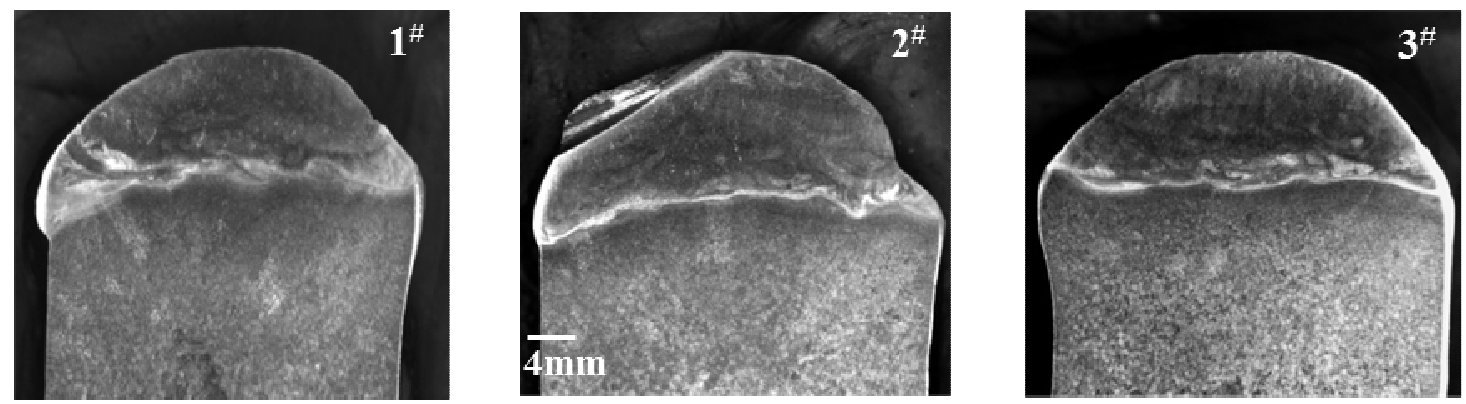

Fig. 2 Cross-section Photographs of the Cladded Layers for Three Different TIG Process Parameters

Figure 1 and Figure 2 show that each cladding area formed is about $80 \mathrm{~mm}$ x $40 \mathrm{~mm}$ and the thickness of each cladded layer is around $8 \mathrm{~mm}$. The cladded layer of the number $2^{\#}$ shows a uniform thickness (Fig 1b) which was produced with stable TIG process parameters. So the welding parameter of the number $2^{\#}$ was selected to prepare a qualified cladding layer for tribo-test investigation. Two intermetallic reference materials of NAC-alloy and its composite were produced by HIP process. The powders of NAC-alloy for HIP process were prepared by using Plasma Rotating Electrode Process (PREP). The PREP system was evacuated to 0.1 bars to minimize oxidation of the powders formed. The chamber was then filled with argon to attain a clean atmosphere. The electrode rod of the master NAC-alloy is accelerated up to the desired speed of rotation, $14500 \pm 500 \mathrm{rpm}$. An argon plasma arc is then ignited and the plasma jet melts tip of the rotating rod. A fusion film is formed on the front end of rod, which disintegrates into small liquid metal droplets as a consequence of action of centrifugal force. Due to surface tension effects and enough time for spheroidisation, the droplets are spherical. On their trajectories towards the chamber wall, the droplets solidify rapidly in the inert atmosphere and form spherical solid particles. The powder sizes of NAC-alloy and $\mathrm{Cr}_{3} \mathrm{C}_{2}$ particles applied for HIP processed are in a range of $45 \mu \mathrm{m}-120 \mu \mathrm{m}$, respectively. The density of NAC-alloy and $\mathrm{Cr}_{3} \mathrm{C}_{2}$ particles used for calculating volume composition of the composites are $7.25 \mathrm{~g} / \mathrm{cm}^{3}$ and $6.68 \mathrm{~g} / \mathrm{cm}^{3}$, respectively. The HIP process data are $1130-1160{ }^{\circ} \mathrm{C}$ as heating temperature under $140 \mathrm{MPa}$ for 3 hours. Dimension of the HIP processed material is $\Phi 70 \mathrm{~mm} \times 150 \mathrm{~mm}$.

\section{Characterization of the Cladded Layer}

Chemical analysis of the cladded layer shows $\mathrm{Ni}-2.33 \mathrm{C}-29.50 \mathrm{Cr}-7.46 \mathrm{Al}-7.99 \mathrm{Fe}$ (in wt. \%) composition. Comparing to the initial composition of the welding wire Ni-2.5C-30Cr-9Al-0.02B (wt. \%), the cladded layer clearly shows less contents of $\mathrm{Ni}, \mathrm{Al}, \mathrm{Cr}$ and $\mathrm{C}$ elements, but higher $\mathrm{Fe}$ content. Cladding process may result in loss of $\mathrm{C}$ and $\mathrm{Al}$ by oxidation ${ }^{[7]}$. It is obvious that the content deviations of $\mathrm{Cr}$ and $\mathrm{Fe}$ were initiated due to dilution during welding process.

The cladded layer was analyzed by means of Holland Panalytical X'per Pro MPD X-ray diffraction spectrometer to identify phase constitution of the material. The $\mathrm{Cu}-\mathrm{K} \alpha \mathrm{X}$-ray radiation with wavelength of $1.5406 \AA$ was used to get the diffraction patterns. The XRD pattern (Figure 3) reveals that there are four phases existed in the cladded layer which is $\mathrm{Ni}_{3} \mathrm{Al}-\mathrm{NiAl}-, \mathrm{M}_{3} \mathrm{C}_{2-}$, and $\mathrm{M}_{7} \mathrm{C}_{3}$-types. 


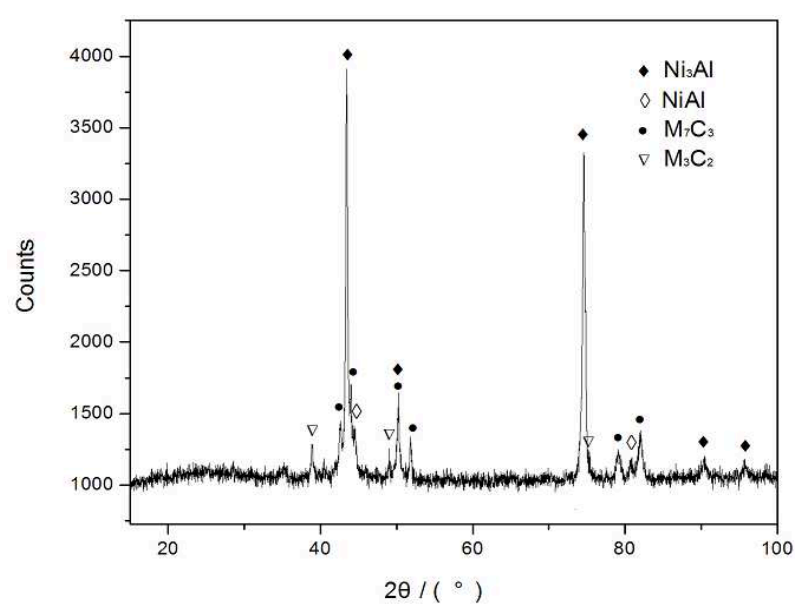

Fig. 3 XRD-spectrum of the Cladded Layer Prepared by Parameter of the Number $2^{\#}$

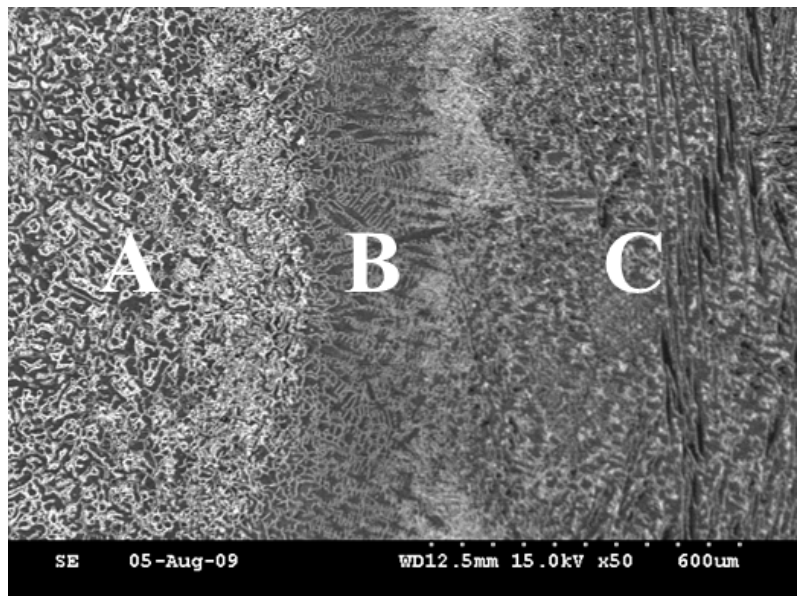

Fig.4 BEI from a Cross-section of the Cladded Layer on (A) Based Material, (B) Fusion Layer and (C) Welding Material

A scanning electron microscope (SEM) equipped with energy dispersive spectrometer (EDS) was utilized to evaluate quality of the testing sample and perform the microstructure analysis. Figure 4 is a backscattering electron image (BEI) from a cross-section of the cladded layer. Three different morphology zones were observed which are based material (A), fusion layer (B) and welding material (C). Furthermore, a good metallurgical bonding can also be observed in the microstructure.

Figure 5 (a) and (b) show backscattering electron images of the HIP processed $\mathrm{Ni}{ }_{3} \mathrm{Al} / \mathrm{Cr}_{3} \mathrm{C}_{2}$ composite and the cladding layer, respectively. It is clearly observed that the morphology of the carbides in these two microstructures is diverse. 


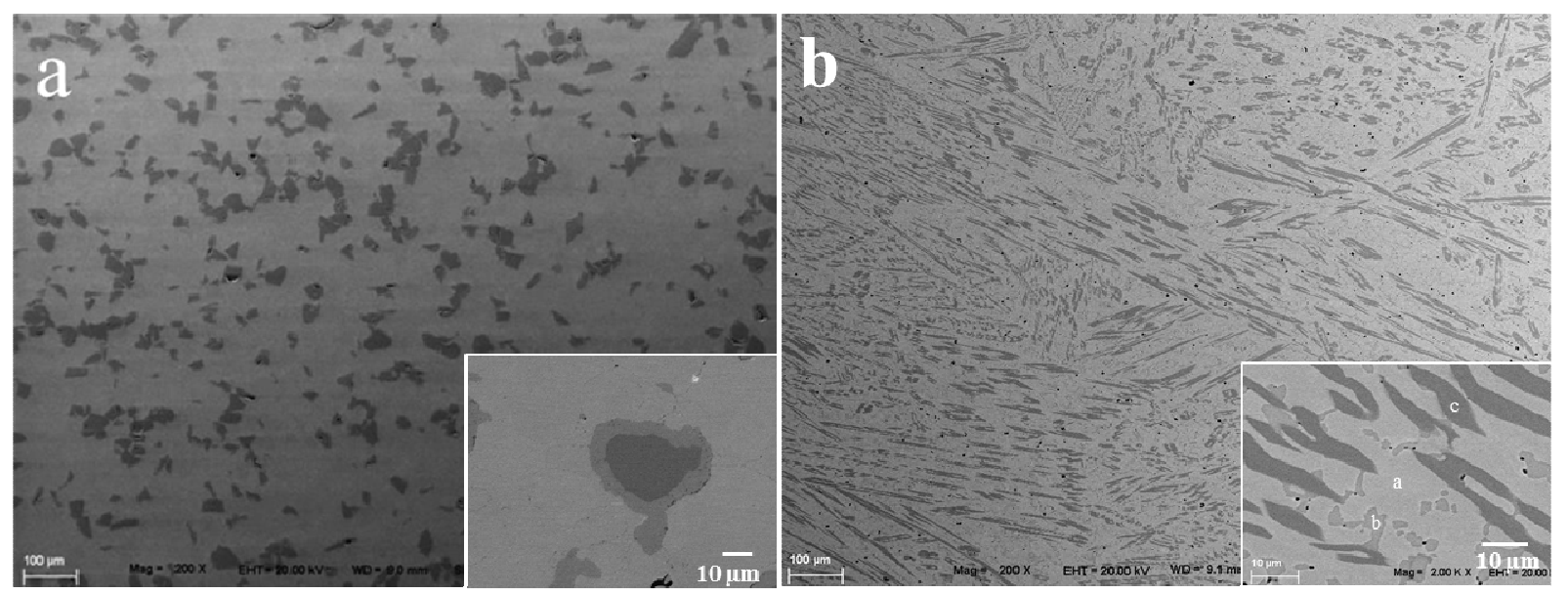

Fig. 5 BEI of (a) HIP Ni $\mathrm{Al}_{3} / \mathrm{Cr}_{3} \mathrm{C}_{2}$ Composite from Pin 2 and (b) the Cladded Layer from Pin1.

The $\mathrm{Cr}_{3} \mathrm{C}_{2}$-particles in the HIP bulk composite reacted with $\mathrm{Ni}_{3} \mathrm{Al}$-matrix and formed a good metallurgical bonding with a light grayish boundary area as shown in the inset Figure 5a. From our previous study ${ }^{[10]}$, EDS analysis revealed that the grey reaction zones have higher content of $\mathrm{Cr}$ as compared to the matrix, but lower Ni- and Fe-contents. This reaction zone is formed due to the diffusion process during HIP process. The composition of the matrix was same as the $\mathrm{Ni}_{3} \mathrm{Al}_{\text {-based }}$ alloy. Figure $5 \mathrm{~b}$ is a backscattering electron image of the cladded layer and the inset figure shows three different phases which were identified by EDS analysis as $\mathrm{Ni}_{3} \mathrm{Al}-$, NiAl-phases and carbides represented by a, b and c respectively. The in-situ formed carbides (Figure 5b) are distributed in the $\mathrm{Ni}_{3} \mathrm{Al}$-matrix with as lamella-like carbides. A secondary phase was also formed in the specimen and the $\mathrm{Al}$ content $(25.09$ at. \%) in this secondary phase was much higher than the $\mathrm{Al}$ content (12.44 at. $\%$ ) of the matrix. Fe-content was detected as 14.55 at. $\%$ in the matrix and 8.80 at. $\%$ in the secondary phase. The $\mathrm{Cr}$ content in $\mathrm{Ni}_{3} \mathrm{Al}$-matrix and $\mathrm{NiAl}$-phase were also recorded as 16.52 at. \% and 7.01 at. $\%$, respectively. Considering $\mathrm{Fe}$ - and $\mathrm{Cr}$-elements with equivalent opportunity to replace Ni- and Al- position in crystals of $\mathrm{Ni}_{3} \mathrm{Al}$ and $\mathrm{NiAl}$, the matrix should be specified as $\mathrm{Ni}_{3} \mathrm{Al}-$ phase, and the secondary phase as NiAl-type. The reason to form NiAl phase in the cladded layer is due to fast cooling rate during the TIG process, resulting in the non-equilibrium microstructure. The results from the analytical study can be coupled to the experimental data of tribological tests for understanding and evaluating wear behavior of the studied materials.

\section{Hardness Measurement}

Vickers hardness on the cross section of cladded layer was measured by using FM-300; the results were referred to a Chinese standard of GB/T 4340.1-1999. The applied load was $200 \mathrm{~g}$ and loading time was 10 seconds. The measurement was applied on three different areas along the cross section of the cladded sample; they are the regions of Welding materials (WM), Fusion layer (FL) and Based materials (BM), see Figure.6 and also referred to Figure.4. In the middle of fusion layer, a central line was selected as an initial position for performing indentation. Therefore, the measured indentations were perpendicular from the central fusion layer (FL) towards the WM and BM. The collected data from two tested specimens $2^{\#}$ and $3^{\#}$ were summarized in Fig.6. 


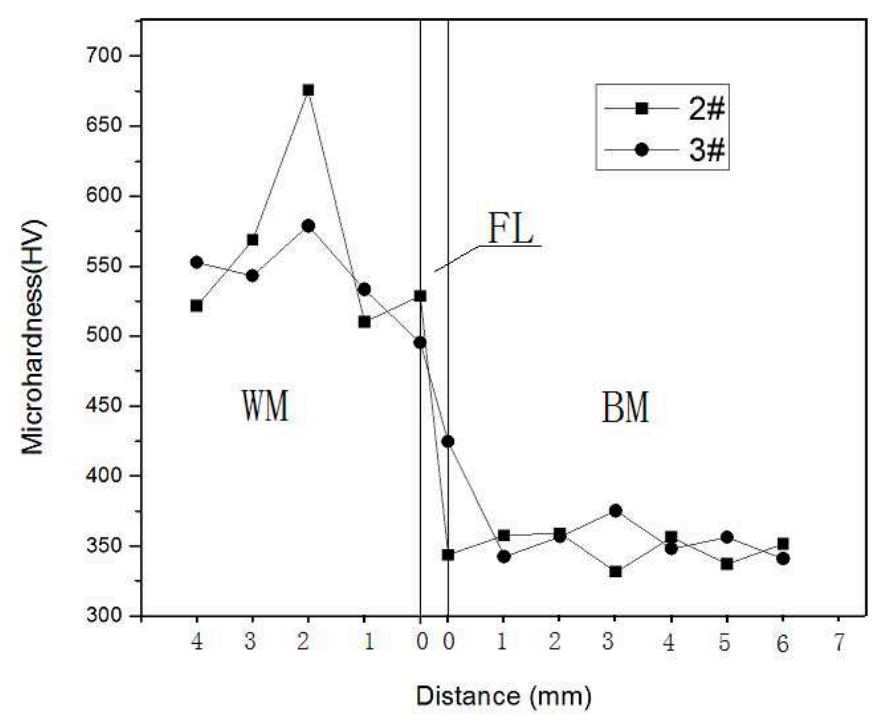

Fig.6 Vickers Hardness Profile on the Cross-section of Two Tested Cladding Layers.

Vickers hardness measurement was also applied on the reference bulk materials and the disk which were used in this investigation. In order to obtain the hardness measurements statistically, 10 indentations on each tested sample were performed. And then, the average Vickers hardness of the tested samples were obtained and listed in table 3.

TABLE 3 MICROHARDNESS OF THE TESTED SAMPLES

\begin{tabular}{|l|c|c|c|c|c|}
\hline Tested samples & Pin 1 & Pin 2 & Pin 3 & Pin 4 & disk \\
\hline HV200 & 558 & 560 & 420 & 240 & 237 \\
\hline
\end{tabular}

Hardness results reveal that carbide addition obviously increased hardness of Pin1 and Pin2, as compared to the monolithic Ni $\mathrm{N}_{3} \mathrm{Al}$-based alloy Pin3. But, the composites of Pin1 and Pin2 which were reinforced by the same volume percentage of carbide addition exhibited the same average hardness, even though Pin1 contains the in-situ formed carbides in its microstructure.

\section{Pin-on-Disk (POD) Test}

To evaluate friction coefficient and wear resistance of the cladded layer and the reference bulk materials, a conventional pin-on-disk tribometer was used. The measurements were performed at room temperature in laboratory with relative humidity of about $45 \%$. The disks with dimension of $\emptyset 30 \mathrm{~mm} \times 4 \mathrm{~mm}$ and the pins with dimension of $\varnothing 3 \mathrm{~mm} \times 16 \mathrm{~mm}$ were machined to the surface roughness $(\mathrm{Ra})$ less than $0.2 \mu \mathrm{m}$. The tests were performed under the normal load of $20 \mathrm{~N}$, corresponding to contact pressure of $2.83 \mathrm{MPa}$. For each specified test, three pin-samples of the tested material were investigated in POD test in order to obtain statistical results. The sliding speed of $8 \mathrm{cms}^{-1}$ was applied as constant value by adjusting the rotation speed $(200 \mathrm{rpm})$ of the disk and the diameter $(\varnothing 8 \mathrm{~mm})$ of the wear tracks. The duration of sliding time was 6 hours. Wear volumes of the pin-samples were calculated from weight loss during the test by assuming density of 7.25 $\mathrm{g} / \mathrm{cm}^{3}$ of the cladded layer and HIP processed bulk composite. Wear volumes of the disks were measured accurately by using computerized three-axis profilometer (Taylor-Hobson). Wear tracks of the disks in 3D profiles were also mapped. The results on sliding wear in this study are demonstrated in terms of Archard`s specific wear rate $(\mathrm{mm} 3 / \mathrm{N} \cdot \mathrm{m})$ by the following formula.

Specific wear rate $=\mathrm{V} / \mathrm{F} \times \mathrm{S}$.

where $\mathrm{V}$ is the worn volume in $\mathrm{mm}^{3}, \mathrm{~F}$ is the applied normal load in Newton and $\mathrm{S}$ is the total sliding distance in meter. 


\section{Friction Coefficient}

The friction coefficients of the testing cladded layer and the reference composite were investigated under the load of $20 \mathrm{~N}$. The measured friction coefficients of the cladded layer and the HIP processed $\mathrm{Ni}_{3} \mathrm{Al} / \mathrm{Cr}_{3} \mathrm{C}_{2}$ composite were $0.13 \pm 0.02$ and $0.68 \pm 0.02$, respectively, see Figure 7 . The friction coefficient of the HIP processed monolithic NAC-alloy $(0.45 \pm 0.02)$ and the commercial vermicular graphite cast iron $(0.48 \pm 0.02)$ from our previous investigation [9] were also given in the figure, as evaluation references.

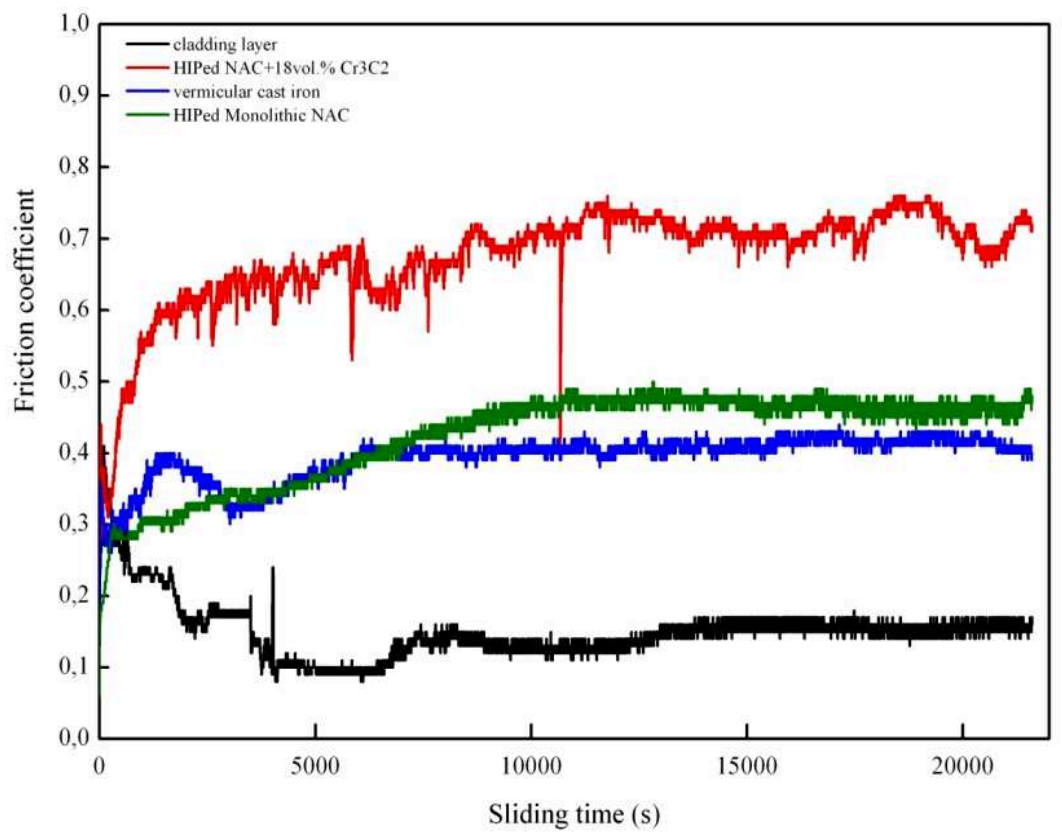

Fig. 7 Friction Coefficients of the Cladded Layer from Pin1, the References $\mathrm{Ni}_{3} \mathrm{Al} / \mathrm{Cr}_{3} \mathrm{C}_{2}$ Composite from Pin2, Monolithic NAC-alloy from Pin3 and the Commercial Vermicular Graphite Cast Iron from Pin4.

\section{Specific Wear Rate}

The specific wear rates of the pins and disks were also measured under the normal load of $20 \mathrm{~N}$. The calculated values were illustrated in Figure 8. The specific wear rates of HIP monolithic NACalloy and the vermicular cast iron from our previous study ${ }^{[9]}$ were also collected in the Figure 8.

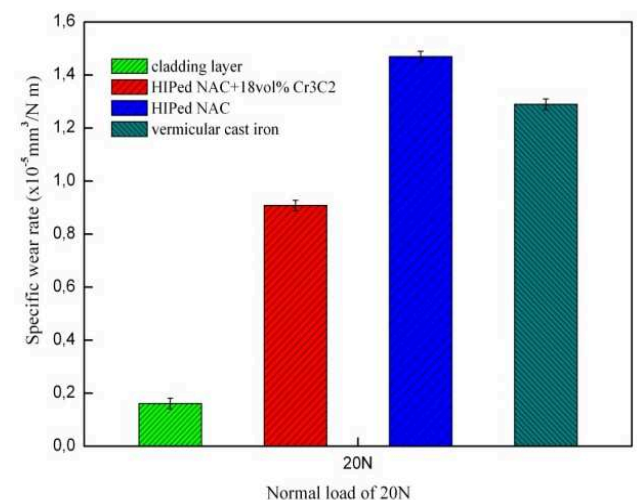

(a)

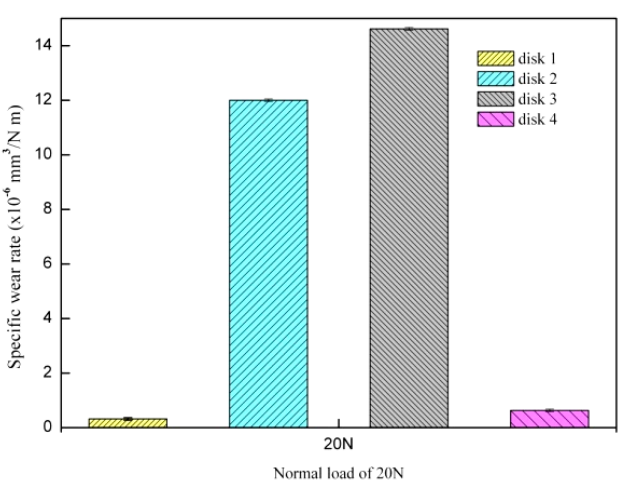

(b)

Fig. 8 Shows Specific Wear Rates of the Cladded layer, HIP Ni3Al/Cr3C2 Composite, Monolithic HIP NAC-alloy and Vermicular Cast Iron from (a), and Specific Wear Rates of the Corresponding Disks from (b). 
The cladded layer clearly exhibited lower specific wear rate $0.162 \times 10^{-5} \mathrm{~mm}^{3} / \mathrm{N} \cdot \mathrm{m}$ as compared to the commercial cast iron $1.29 \times 10^{-5} \mathrm{~mm}^{3} / \mathrm{N} \cdot \mathrm{m}$ in the same working condition. The specific wear rate $\left(0.91 \times 10^{-5} \mathrm{~mm}^{3} / \mathrm{N} \cdot \mathrm{m}\right)$ of the HIP processed $\mathrm{Ni}_{3} \mathrm{Al}+18$ vol. $\% \mathrm{Cr}_{3} \mathrm{C}_{2}$ composite was reduced as compared to the specific wear rate $\left(1.47 \times 10^{-5} \mathrm{~mm}^{3} / \mathrm{N}\right)$ of the monolithic NAC-alloy. Meanwhile, the counterpart disk against to cladded layer showed lower specific wear rate $\left(0.319 \times 10^{-6}\right.$ $\left.\mathrm{mm}^{3} / \mathrm{N} \cdot \mathrm{m}\right)$ as compared to the specific wear rate $\left(0.633 \times 10^{-6} \mathrm{~mm}^{3} / \mathrm{N} \cdot \mathrm{m}\right)$ of the disk against to vermicular cast iron. The disk worn off by the HIP processed $\mathrm{Ni}_{3} \mathrm{Al}-18$ vol. $\% \mathrm{Cr}_{3} \mathrm{C}_{2}$ composite showed the high specific wear rate of $12 \times 10^{-6} \mathrm{~mm}^{3} / \mathrm{N} \cdot \mathrm{m}$. Clearly, the HIP processed $\mathrm{Ni}_{3} \mathrm{Al}+18$ vol. $\% \mathrm{Cr}_{3} \mathrm{C}_{2}$ composite were working inadequately with its disk. Figure 9 ( $\mathrm{a}$ and $\mathrm{b}$ ) illustrated the 3-D images of the disks worn off by the cladded layer and the HIP processed $\mathrm{Ni}_{3} \mathrm{Al}+18$ vol. $\% \mathrm{Cr}_{3} \mathrm{C}_{2}$ composite, which revealed that the disk worn off by the HIP processed $\mathrm{Ni}_{3} \mathrm{Al}+\mathrm{Cr}_{3} \mathrm{C}_{2}$ composite had severe and deeper wear tracks on the surface as compared to the disk worn off by the cladded layer. It indicates that the artificially added coarse hard particles $\mathrm{Cr}_{3} \mathrm{C}_{2}$ induced mostly the asperities on the worn surface which caused the severe wear tracks on the counterpart disk. In contrast, in-situ formed Cr-carbides from the cladded layer were coupled to smooth worn surface of the disk.

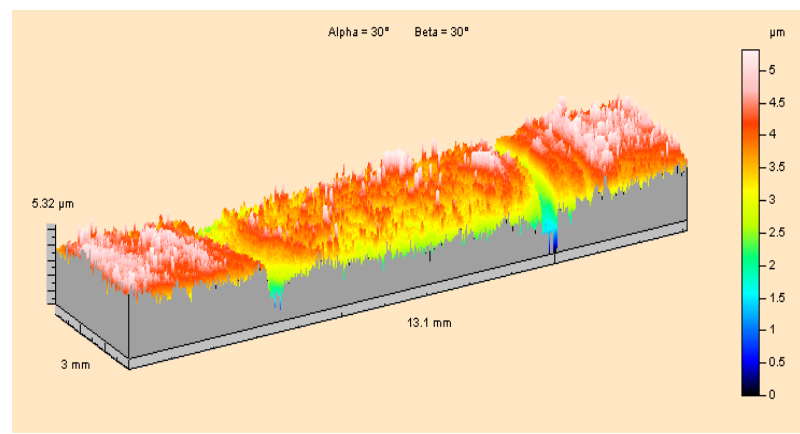

(a)

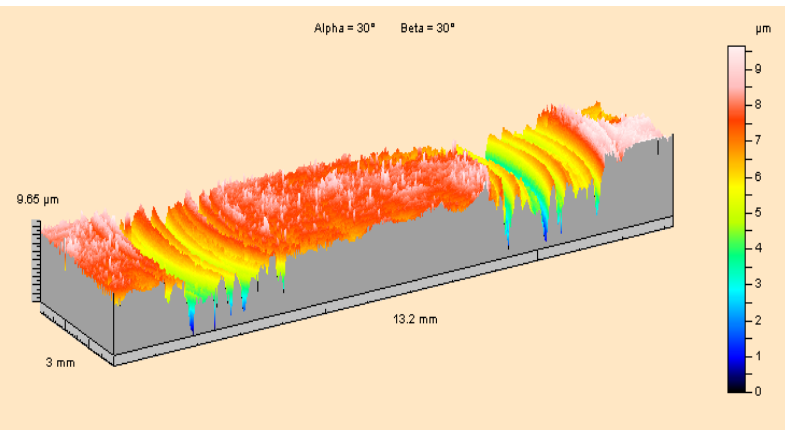

(b)

Fig.9 3-D Images Profiles of the Disk Worn Surface Against to (a) the Cladded Layer and (b) HIP Processed $\mathrm{Ni} 3 \mathrm{Al} / \mathrm{Cr} 3 \mathrm{C} 2$ Composite.

\section{Discussion}

It is well known that the mechanical properties of a MMC (Metal-matrix composites) are important in determining their tribological behavior. During tibological interaction between two surfaces, temperature rises significantly at and near the surface, and the mechanical properties of the composites at elevated temperatures may be of direct relevance. The dispersed hard particles such as chromium carbides are helpful in retaining the high temperature strength of the matrix. During TIG process, chromium and carbon are partially dissolved in the $\mathrm{Ni}_{3} \mathrm{Al}$ matrix and resulted in solidsolution strengthening. Then, the dispersed Cr-carbides were formed which increased hardness of the cladded layer. In our previous study, it indicated that the wear rate of metal-matrix composites decreased with an increase in volume fraction, if the bonding between the matrix and the particles is adequate.

Karin et al. ${ }^{[9]}$ investigated previously the sliding wear behavior of the $\mathrm{Ni}_{3} \mathrm{Al}$-based NAC-alloy and its composites reinforced by 6 vol. $\% \mathrm{Cr}_{3} \mathrm{C}_{2}$-particles under unlubricated condition. The experimental results revealed that the bulk monolithic NAC-alloy has similar friction coefficient and specific wear rate to commercial vermicular cast iron used in ship engines under same testing condition. Definitely, the addition of $\mathrm{Cr}_{3} \mathrm{C}_{2}$ hard particles reduced wear on both sides of pin and disk. The phenomenon was more obvious under the high applied load of $40 \mathrm{~N}$ testing conditions. Furthermore, considering other excellent physical, chemical and mechanical properties of the $\mathrm{Ni}_{3} \mathrm{Al}$-based intermetallic materials, the investigation has indicated that it could be meaningful and possible to develop $\mathrm{Ni}_{3} \mathrm{Al}$-matrix composites, reinforced by the hard $\mathrm{Cr}_{3} \mathrm{C}_{2}$-particles for tribological applications. Therefore, the high contents of $\mathrm{Cr}$-carbides $(18$ vol. \%) composites were prepared by both HIP and cladding process in this study. Clearly, the $\mathrm{Ni}_{3} \mathrm{Al} / \mathrm{Cr}_{3} \mathrm{C}_{2}$ intermetallic cladded layer on 
the steel substrate performed superior wear behavior as compared to the wear-resistant vermicular cast iron and the other $\mathrm{Ni}_{3} \mathrm{Al}$-based materials. The $\mathrm{Ni}_{3} \mathrm{Al} / \mathrm{Cr}_{3} \mathrm{C}_{2}$ intermetallic cladded layer exhibited the lowest friction coefficient $(0.13 \pm 0.02)$ in this group. It was considered that the superior wear behaviors of the $\mathrm{Ni}_{3} \mathrm{Al} / \mathrm{Cr}_{3} \mathrm{C}_{2}$ intermetallic cladded layer were connected to its unique microstructure. Two types of carbides with different sizes were in-situ formed in the $\mathrm{Ni}_{3} \mathrm{Al}$-matrix during solidification of the TIG process. They are distributed homogeneously with less spacing in the layer material compared to the interval distance of the artificially added carbide in the HIP processed $\mathrm{Ni}_{3} \mathrm{Al} / \mathrm{Cr}_{3} \mathrm{C}_{2}$ composite. Furthermore, the in-situ formed hard NiAl-particles will also be beneficial to the wear properties of the layer material. It should be noticed that the secondary NiAlphase increased the total volume percentage of the hard phase in the microstructure, although the amounts of the chromium carbides in both of the $\mathrm{Ni}_{3} \mathrm{Al} / \mathrm{Cr}_{3} \mathrm{C}_{2}$ intermetallic cladded layer and the HIP processed composite are in the same range of $18 \mathrm{vol}$. \%. Therefore, it is reasonable to consider that the material with hard particles with less spacing will protect the matrix more effectively and resulting in low friction coefficient with low specific wear rate at same wear conditions.

The present study suggests that such cladded intermetallic layer worked adequately with its grey cast iron disk during sliding wear and obtained the specific wear rate as $0.319 \times 10^{-6} \mathrm{~mm}^{3} / \mathrm{N} \cdot \mathrm{m}$. This value is only about $50 \%$ the wear rate $\left(0.633 \times 10^{-6} \mathrm{~mm}^{3} / \mathrm{N} \cdot \mathrm{m}\right)$ induced by the reference vermicular cast iron under the same wear testing conditions. The HIP processed $\mathrm{Ni}_{3} \mathrm{Al}+18$ vol. $\% \mathrm{Cr}_{3} \mathrm{C}_{2}$ composite worked with its counterpart disk shows low wear resistance and induced high specific wear rate of $12 \times 10^{-6} \mathrm{~mm}^{3} / \mathrm{N} \cdot \mathrm{m}$. This reveals that the microstructure of the composite played a key role and influenced the wear properties. Hence, the fine microstructure is preferable in all aspects. Furthermore, the composition of the matrix in the HIP processed $\mathrm{Ni}_{3} \mathrm{Al} / \mathrm{Cr}_{3} \mathrm{C}_{2}$ composite was maintained invariant during the heating process. In contrast, the added Cr-element in the welding wire was partially dissolved in the solid $\mathrm{Ni}_{3} \mathrm{Al}$-matrix which strengthened and hardened the material resulted in improved the wear-resistance.

\section{Conclusions}

From the study, several points can be concluded as follows:

The $\mathrm{Ni}_{3} \mathrm{Al}-18$ vol. \% Cr-carbides intermetallic cladded layer on the high strength steel substrate worn off against the grey cast iron disk exhibited less friction coefficient $0.13 \pm 0.02$ which is one quarter in magnitude of the friction coefficient $(0.48 \pm 0.02)$ from the vermicular cast iron under the same testing condition.

The specific wear rate of the $\mathrm{Ni}_{3} \mathrm{Al} / \mathrm{Cr}_{3} \mathrm{C}_{2}$ composite cladded layer is $0.162 \times 10^{-5} \mathrm{~mm}^{3} / \mathrm{N} \cdot \mathrm{m}$, which is almost equal to one tenth in magnitude of wear rate $\left(1.29 \times 10^{-5}\right)$ of the vermicular cast iron under the load of $20 \mathrm{~N}$.

The intermetallic $\mathrm{Ni}_{3} \mathrm{Al} / \mathrm{Cr}_{3} \mathrm{C}_{2}$ cladded layer worked more adequately with its grey cast iron disk, comparing to the reference vermicular cast iron and other tested intermetallic matrix composites. A specific wear rate $0.319 \times 10^{-6} \mathrm{~mm}^{3} / \mathrm{N} \cdot \mathrm{m}$ of the disk was obtained under the testing condition.

The outstanding properties of the $\mathrm{Ni}_{3} \mathrm{Al} / \mathrm{Cr}_{3} \mathrm{C}_{2}$ intermetallic cladded layer on wear were related to its unique microstructure. The in-situ formed hard $\mathrm{Cr}$-carbides of various sizes with the small spacing may play a key role on the tribological properties of the cladded layer.

The wear behavior of the $\mathrm{Ni}_{3} \mathrm{Al} / \mathrm{Cr}_{3} \mathrm{C}_{2}$ intermetallic cladded layer may also respond to the in-situ formed un-equilibrium hard $\mathrm{NiAl}$-particles and $\mathrm{Cr}$-alloyed $\mathrm{Ni}_{3} \mathrm{Al}$-matrix. Therefore, the cladding process is promising selection to produce wear-resistant layer of $\mathrm{Ni}_{3} \mathrm{~A}$-matrix composites in further investigation.

\section{Acknowledgements}

The authors are grateful for the financial support given by the Swedish VINNOVA and Chinese MOST for the international collaborative research projects P32737-1 and P32737-2 and appreciate the Department of Manufacturing Engineering and Engineering Management, City University of Hong Kong for allowance to use the facilities for tribological evaluation. Here authors also would 
greatly appreciate Li Jikang, the senior of nercast in CISRI, Beijing for her guidance and encouragement through this work. The authors would like to thank Dr. Kumar Babu Surreddi reviewer for his careful polish and insightful comments that helped us improve this paper.

\section{References}

[1] Marquardt B. J., Wert J. J., Wear Induced Deformation of Ni3Al, (Fe,Co)3Al and (FeNi)3V [J]. Proc. Mater. Res. Soc.1985, 39:247

[2] Blau P. J., DeVore C. E.Sliding Behaviour of Alumina/Nickel and Alumina/Nickel Aluminide Coule at Room and Elevated Temperature [J]. J Tribology, 1988, 110: 646.

[3] Bonda N. R., Rigney D. A., Unlubricated Sliding Wear of Nickel Aluminides at Room Temperature and $400{ }^{\circ} \mathrm{C}[\mathrm{J}]$. Proc. Mater. Res. 1989, 133: 585.

[4] Blau P. J., DeVore C. E., Temperature Effects on the Break-in of Nickel Aluminide Alloys [C] Proc. 1989 Wear of Materials Conference, American Society of Mechanical Engineers, 1989: 305.

[5] Blau P. J., DeVore C. E.,Sliding Friction and Wear Behaviour of Several Nickel Aluminide Alloys under Dry and Lubricated Condition [J]. Tribol. Ins., Oct. 1990: 226.

[6] Johnson M., Mikkola D. E., March P. A. et al, The Resistance of Nickel and Iron Aluminides to Cavitation Erosion and Abrasive Wear [J]. Wear (1990) 140:279.

[7] Shangping Li, Di Feng, Heli Luo, Microstructure and Abrasive Wear Performance of Chromium carbide Reinforced Ni3Al Mareix Composite Coating, Surf. Coat. Tech. 201 (2007), 4542:4546.

[8] Compilatory group of machine-producing technology and material (Ed.), Handbook of machine producing technology and material (second part), Machine Industry Press, 1993, 674:xxx.

[9] Karin Gong, Zhifeng Zhou, P.W.Shum, et al, Tribological Evaluation on Ni3Al-based Alloy and Its Composites Under Unlubricated Wear Condition [J] Wear, (2011) 270, 195:203

[10]Karin Gong, Heli Luo, D. Feng, et.al, Wear of Ni3Al-based Materials and Its ChromiumCarbide Reinforced Composites [J] Wear, (2008) 265, 1751:1755. 
Materials Science and Engineering Technology

10.4028/www.scientific.net/AMR.936

Study on Wear Behaviors of $\mathrm{Ni}_{3} \mathrm{Al} / \mathrm{Cr}$-Carbides Cladding Layer on High Strength Steel Substrate 10.4028/www.scientific.net/AMR.936.1273 